\title{
Grand challenges in bioenergy and biofuel research: engineering and technology development, environmental impact, and sustainability
}

\author{
Jacob N. Chung* \\ Department of Mechanical and Aerospace Engineering, University of Florida, Gainesville, FL, USA \\ ${ }^{*}$ Correspondence: jnchung@ufl.edu \\ Edited by: \\ Junye Wang, Athabasca University, USA \\ Reviewed by: \\ Arthur Ragauskas, Georgia Institute of Technology, USA
}

Keywords: biomass, sustainability, energy, lignocellulosic biofuel, feedstock, biosyngas, environment

\section{INTRODUCTION}

POTENTIAL OF BIOMASS AS A SOLUTION FOR FUTURE ENERGY NEEDS

Greenhouse effects and global climate change are controversial and critical issues that impact on the energy industry, government policy making, and society (Holdren, 2001; Kalicki and Goldwyn, 2005). Longterm economic sustainability of the energy, transportation, and manufacturing sectors would require the adoption of a range of renewable and sustainable fuels (Wilk, 2002). Such energy sources should carry high energy contents with minimal emission of greenhouse gases. Importantly, the resource development and production processes of these fuels should have minimal impact on the food chain, water supply, land use, and environment. Nuclear, solar, geothermal, wind, and biomass are all excellent fuel sources, since they are nearly carbon-neutral.

Biomass is one of the most important primary, renewable energy resources for a projected renewable and sustainable energy future. There is an urgent need to develop technologies which enable the conversation of lignocellulosic and municipal solid waste (MSW) biomass resources into useful energy, from thermodynamic efficiency and system technology standpoints, as well as from an environmental impact standpoint.

As the world faces significant energy supply and security challenges due to our dependence on petroleum and oil, the need for sustainable alternatives has received great attention. To achieve energy security and independence in the near future, and in the long run to prepare for the post-oil energy needs, the report from the recent US National Science Foundation - Department of Energy (NSF-DOE) Workshop report (Huber, 2007) concluded that liquid biofuels produced from lignocellulosic biomass can significantly reduce our dependence on oil, create new jobs, improve the rural economy, reduce greenhouse emissions, and ensure energy security. The report also emphasized that the bottleneck for lignocellulosic biomass-derived fuels is the lack of technology for the efficient conversion of biomass into liquid fuels. New technologies are thus needed to replace fossil fuels with renewable and sustainable energy resources.

For example, in the US reliable estimates of renewable and sustainable lignocellulosic forest, agricultural biomass, and MSW (likewise mostly biomass) range from 1.5 to 2 billion dry metric tons per year (Huber, 2007); these biomass resources thus could contribute 10 times more to the US primary energy supply (PES) than now. Another forecast in the same report (Huber, 2007) claims that all forms of biomass and MSW have the potential to replace up to $60 \%$ of US consumption of crude oil; and that lignocellulosic biomass resources are significantly cheaper (at the equivalent of US\$ 15 per barrel o) than petroleum. Since lignocellulosic biomass is the fibrous, woody (mainly hemicellulose and lignin), and generally inedible portion of plants, there is no tradeoff with the production of food crops (i.e., cellulosic biomass). As biomass widely available in many parts of the world, environmentally friendly, and renewable, its potential to help meet the world energy demand has been widely recognized. In a review, Kirtay (2011) concluded that biomass energy has the potential to be "modernized" worldwide, that is, it could be produced and used efficiently and at competitive cost, generally in the more convenient forms of gases, liquids, or electricity. Biomass will certainly play an important role in the future global energy infrastructure for the generation of power and heat and the production of chemicals and fuels. In a thermodynamic study, Corradetti and Desideri (2007) found that hydrogen fuel can be produced from gasification of woody biomass coupled with steam-methane reforming and a water-gas shift reaction in a large-scale industrial plant with an efficiency of $62 \%$ - comparable to those of existing process technologies. Corradetti and Desideri (2007) also reported that an overall efficiency of $44 \%$ can be obtained for power production through a gas-steam combined cycle that uses woody biomass gasification as energy source. The US Natural Resources Defense Council has projected that an ambitious plan for the production of lignocellulosic biofuels could yield 7.9 million barrels of oil per day by 2050 in the US alone, which is over $50 \%$ of current total oil used in transportation (Greene, 2004).

The primary research and development objectives of bioenergy and biofuel should be aimed at: (1) developing the best scientific, engineering, and technology solutions for converting lignocellulosic and MSW biomass together with agricultural and forest residues into clean energy (e.g., liquid fuels, chemical feedstock, electricity, and mechanical power); (2) minimizing water consumption and detrimental impacts of energy production on the environment (air pollution and global warming); and (3) addressing long-term availability and sustainability issues. 
Figure 1 shows the biomass-to-energy and solid waste-to-energy conversion paths. There are two parallel approaches: the first flow process focuses on the biochemical conversion of biomass to biofuels, while the second uses thermochemical methods to produce oil and synthesis gas (syngas) through pyrolysis and gasification of lignocellulosic and solid waste biomass (e.g., energy crops, forest products, and agricultural residues), respectively. For both paths, the challenges we face today are addressed next in the areas of engineering and technology development, environmental impact and sustainability.

\section{ENGINEERING AND TECHNOLOGY DEVELOPMENT DEVELOPMENT OF FEEDSTOCK}

The main feedstock should include algae, bioenergy crops, waste, and residues. Currently, non-food-based biomass feedstock primarily relies on supplies from agricultural residue and waste. However, these resources are insufficient to allow bioenergy and biofuel to play a major role in the renewable and alternative energy market. As a result, research is urgently needed to develop oil- and carbohydraterich plant strains, and lignocellulosic biomass and aquatic energy crops and grasses that are designed through breeding and management to fit the intended conversion process (bio- and thermochemical) for maximum energy yields. Research and development should also seek crops that do not compete with food crops and are fast growing, resistant to disease and parasites, and requiring minimal amounts of land, water, and fertilizers.

\section{BIOCHEMICAL AND THERMOCHEMICAL} BIOMASS CONVERSION TECHNOLOGIES

Biochemical fermentation conversion processes consist of many steps: biomass pretreatment and fractionation, enzymatic hydrolysis, saccharification, microbial fermentation, and product separation and purification process. Research is needed to strongly enhance efficiency for each of these intrinsic processes. Virkajarvi et al. (2009) pointed out that the challenges are associated with the raw materials availability in reasonable quantity and competitive prices. Additionally, the pretreatment, microbial fermentation, and concentration of sugar in processing need improvement. Furthermore, engineering studies are required to design, optimize, and scale-up the biochemical conversion system, which include both the biochemical reactor and the supporting and auxiliary components.

In the thermochemical approach, gasification is the main process to convert biomass into synthesis gas ("syngas"; composed mostly of $\mathrm{H}_{2}, \mathrm{CO}, \mathrm{CO}_{2}$, $\mathrm{CH}_{4}$, water vapor, and trace impurities). Thermochemical gasification is likely to be

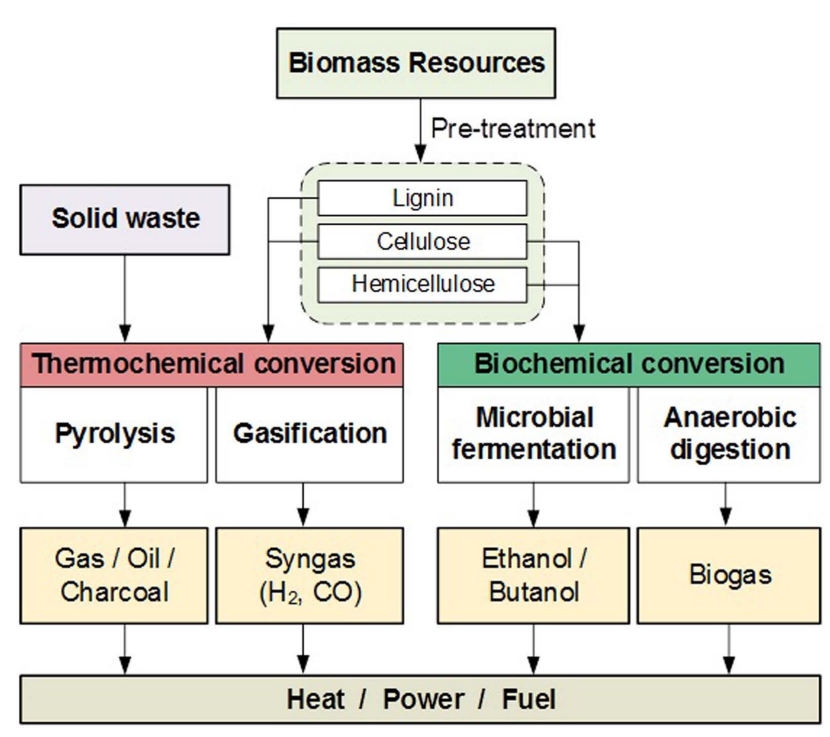

FIGURE 1 | Flow chart for biomass conversion and solid waste conversion to energy paths.

one of the most cost-effective and efficient energy conversion processes. Syngas is a gaseous fuel that is already used in combustion furnaces and fuel cells, and as fuel for gas turbines and IC engines. Gasification is achieved by reacting the biomass feedstock at high temperatures (above $700^{\circ} \mathrm{C}$ but without combustion, with a controlled amount of oxygen with or without steam. The thermal energy (heat) required for gasification can be obtained internally from the combustion of a portion of the feedstock (through the oxygen-blown partialoxidation autothermal process); or from an external source (an allothermal process), for example by electricity in the case of plasma gasifiers or using a heated bed material. Recently, allothermal gasification by high-temperature steam (Chang et al., 2011; Umeki et al., 2012) has gained more attention; this is because high-temperature steam serves as the heat source and the promoter for the water-gas shift reaction that converts more char into to hydrogen. Based on the above discussion, the challenges associated advancing the gasification technology thus should come from finding ways to improve the thermal and chemical gasification processes (e.g., developing effective catalysts and additives). Additionally, the engineering research is required to design, optimize, and scale up the gasification system that includes the gasifying reactor and the supporting and auxiliary components.

Biosyngas can be a useful fuel, but converting it to liquid hydrocarbon fuels would produce an even more energy-dense substance comparable to petroleum-derived diesel and gasoline. The Fischer-Tropsch synthesis reaction is the key chemical reaction that converts syngas to liquid hydrocarbon. According to Huber (2013), biomass feedstocks are fundamentally different from petroleum feedstocks because the high-oxygen content of biomass leads to low thermal stability and a high degree of difficulty in controlling the functionality. Huber (2013) further suggests that a major scientific challenge for the gas-to-liquid synthesis is to efficiently and selectively remove oxygen from biomassderived molecules, and to functionalize this feedstock into the targeted molecules that are compatible with petroleum-based liquid fuels. Heterogeneous catalysis and chemical engineering is the key to the efficient conversion of biomass-derived molecules into fuel. It is thus essential to understand and control 
these chemical reactions by developing clean catalytic technology and chemical process for advancing biomass-to-biofuel conversion. Furthermore, given that the gas-to-liquid synthesis is an endothermic reaction with a narrow effective reactor temperature range, it is necessary to take thermal management into account when designing reactors.

Another important thermochemical conversion method is the fast pyrolysis that is the process of rapid thermal decomposition of organic compounds in the absence of oxygen at $400-500^{\circ} \mathrm{C}$ to produce liquid oils, char, and small amount of gases. Liquid bio-oil from pyrolysis has the potential to contribute significantly to the liquid biofuel supply and as a source of a number of valuable chemicals. However, many challenges (Czernik and Bridgwater, 2004) need to be overcome that include plant scale up, cost reduction, better oil stability and quality, norms and standards for producers and users, environmental health and safety issues in handling, transport, and usage.

\section{ALGAE-BASED TECHNOLOGIES}

Algal biofuels have the potential to strongly contribute to the bioenergy and biofuel industry. Major advantages are their relatively high yield and the lack of competition (e.g., over area, water) with food crops. Research should focus on mobile, modular, and costeffective systems for the cultivation and production of algae locally as the resources tend to distribute over a wide range.

Research and development to find the best catalytic technology and efficient reactor design should continue for the so far proven most effective methods of fermentation of microbial to bioethanol fuel and the production of biodiesel via in situ transesterification of microalgal biomass. A real challenge is finding breakthrough technology for realizing the metabolic engineering of photosynthetic organisms to enhance biofuel production.

\section{ANAEROBIC DIGESTION TECHNOLOGIES}

Besides the technologies discussed above, the anaerobic digestion also holds a promise for a potentially significant contribution to future bioenergy and biofuel production. The anaerobic digestion research should continue on the search for efficient and cost-effective integrated systems to produce bioenergy (methane) and biofertilizers from organic feedstocks, including purpose-grown energy crops, microalgal biomass, crop residues, food and animal waste, and other organic materials.

Anaerobic digestion is a highly complex process that involves immeasurable quantities of biological and chemical reactions all taking place simultaneously. There is a need to increase the scientific understanding of the biological and physiochemical reactions and interactions in a digester. For example, the normal operation of a digester requires the balance of reactions between chemicals and microorganisms which can be lost simply due to the presence of inhibiting agents and toxins. Consequently, the identification of the toxic and inhibiting substances in the reactor and their interactions with the chemicals and microorganisms during the digestion process is critical for the productive operation of the plant. Engineering approaches toward the optimal design of the reactor and the process are also important.

\section{ENVIRONMENTAL IMPACT}

The Energy crisis, air pollution, and greenhouse gases have become the driving force in the shift toward cleaner and renewable fuel alternatives. Biomass is an excellent candidate fuel source as its resource development and production processes impact minimally on the food chain, water supply, land use, and environment. Most importantly, biomass energy can be considered carbon-neutral. However, in the challenge for making biofuels a legitimate candidate, the focus should be placed on a clear understanding of the energy policy, environmental impacts, emission characterization, and Life Cycle Assessment (LCA) associated with the use of biomass for energy. These can be accomplished through:

- Characterizing the emissions from the thermal-chemical, bioconversion, and anaerobic digester plants in terms of their impacts on global warming, climate change, and ecosystems.

- Analyze gaseous emissions and characterize aerosols with aerosol sampling instruments coupled with ion chromatography, atomic absorption, and carbon analysis for their physical and chemical characteristics.

- Utilize the emission information as an input for a larger LCA framework to quantify relevant emissions not only during the operational stage of the thermal-based and bio-based energyproduction processes but also from their associated raw material extraction, use, transportation, and waste disposal stages.

- Quantify corresponding environmental impacts, such as global warming, ozone depletion, among others, and compare to existing fossil fuel-based processes to ensure minimum detrimental environmental impacts.

\section{SUSTAINABILITY}

Today's society is on the threshold of a technological and social revolution in energy production, utilization, and sustainability. Utility regulators, service providers, and customers must make critical, long-term decisions in an ever-changing environment due to regulations and laws driven by local, state, federal, and international government policies. Meeting the challenges in the energy industry posed by climate change policy will assuredly alter electric utility investment plans, drive regulators to adopt innovative policies, and impact customers in multiple ways. Similar concerns are associated with the transportation and manufacturing sectors.

The issues of sustainability of bioenergy and biofuel are complex as the biomass infrastructure is huge and far-reaching, while the science and technology are just in their infancy. However, the policies and regulations for the future establishment of the energy industry being made now create a challenge for scientists and engineers to communicate with policy decision makers. Dale et al. (2013) suggest that scientists and engineers need to come to an agreement to streamline how to measure and report the benefits and risks of various forms of bioenergy in a way that provides the complete picture for the decision makers to weigh on all the potential options.

The Center for BioEnergy Sustainability (CBES) at the US Department of Energy Oak Ridge national laboratory Center for BioEnergy Sustainability (CBES, 2013) is a leading institution for dealing with environmental impacts and the sustainability of biomass production for conversion into biofuels and bio-based products. CBES's aim is to analyze the sustainability (environmental, economic, and social) of current and potential bioenergy production 
and distribution; to identify methods for enhancing the sustainability of bioenergy; and to serve as an independent sources of data and analysis for bioenergy stakeholders and decision makers. It focuses on

- Bioenergy options from a systems perspective

- Sustainability as a combination of environmental, economic, and social concerns

- Appropriate scales for addressing bioenergy sustainability concerns

- Tradeoffs in implications of land-use and land-management decisions

- Quantifying environmental, economic, and social implications of bioenergy choices at local, regional, and global scales

- Lignocellulosic feedstock options and their implications for ecosystem services and social and economic benefits.

\section{CONCLUDING REMARKS}

As elaborated and discussed above, biomass, a carbon-neutral and renewable energy resource, holds a strong potential to provide a major solution to our future energy needs. However, this potential can only be realized through intense collaboration amongst stakeholders to pool available resources necessary to overcome obstacles and challenges.

\section{REFERENCES}

CBES. (2013). Available at: http://web.ornl.gov/sci/ees/ cbes/

Chang, A. C. C., Chang, H. F., Lin, F. J., Lin, K. H., and Chen, C. H. (2011). Biomass gasification for hydrogen production. Int. J. Hydrogen Energy 36, 14252-14260. doi: 10.1016/j.ijhydene.2011.05.105

Corradetti,A., and Desideri, U. (2007). Should biomass be used for power or hydrogen production? J. Eng. Gas Turb. Power 129, 629-636. doi: 10.1115/1.2718226

Czernik, A., and Bridgwater, A. V. (2004). Overview of applications of biomass fast pyrolysis oil. Energy Fuels 18, 590-598.

Dale, V. H., Klein, K. L., Perla, D., and Lucier, A. (2013). Communicating about bioenergy sustainability. Energy Manag. 51, 279-290. doi: 10.1007/ s00267-012-0014-4

Greene, N. (2004). Growing Energy: How Biofuels Can Help End America's Oil Dependence. New York: Natural Resources Defense Council.

Holdren, J. P. (2001). The energy-climate change. Environ. J. 28, 87-97.

Huber, G. W. (2007). "Breaking the chemical and engineering barriers to lignocellulosic biofuels: a research roadmap for making lignocellulosic biofuels a practical reality," in NSF, DOE and American Chemical Society Workshop, Washington, DC.

Huber, G.W. (2013). Available at: http://biofuels.che. wisc.edu/
Kalicki, J. H., and Goldwyn, D. L. (2005). Energy and Security: Toward a New Foreign Policy Strategy. Baltimore, MD: The Johns Hopkins University Press.

Kirtay, E. (2011). Recent advances in production of hydrogen from biomass. Energy Convers. Manag. 52, 1778-1789. doi: 10.1016/j.enconman.2010.11.010

Umeki, K., Namioka, K., and Yoshikawa, K. (2012). Analysis of an updraft biomass gasifier with high temperature steam using a numerical model. Appl. Energy 90, 38-45. doi: 10.1016/j. apenergy.2010.12.058

Virkajarvi, I., Niemela, M. V., Hasanen, A., and Teir, A. (2009). Challenges of cellulosic ethanol. Bioresources 4, 1718-1735.

Wilk, R. R. (2002). "Culture and energy consumption," in Energy: Science, Policy and the Pursuit of Sustainability, eds R. Bent, L. Orr, and R. Barker (Washington, DC: Island Press), 109-129.

Received: 29 July 2013; accepted: 13 September 2013; published online: 30 September 2013.

Citation: Chung JN (2013) Grand challenges in bioenergy and biofuel research: engineering and technology development, environmental impact, and sustainability. Front. Energy Res. 1:4. doi: 10.3389/fenrg.2013.00004 This article was submitted to Bioenergy and Biofuel, a section of the journal Frontiers in Energy Research.

Copyright (c) 2013 Chung. This is an open-access article distributed under the terms of the Creative Commons Attribution License (CCBY). The use, distribution or reproduction in other forums is permitted, provided the original author(s) or licensor are credited and that the original publication in this journal is cited, in accordance with accepted academic practice. No use, distribution or reproduction is permitted which does not comply with these terms. 